\title{
INTERNET ADDICTION IN THE CONTEXT OF POSITIVE PSYCHOLOGY
}

\begin{abstract}
Alexander E. Voiskounsky
Lomonosov Moscow State University

Moscow

Optimal, or flow experience is a psychological construct introduced by M. Csikszentmihalyi; it refers to intrinsic motivation when an activity is worth doing for its own sake and denotes productive work with high concentration on the task, distinct objectives and high level of satisfaction, positive feelings such as enjoyment, balance between the available skills and the task challenges, immediate feedback, as well as temporary loss of self-consciousness and distorted sense of time. This construct is being intensely used in numerous environments connected with the use of information technologies, including specific ones such as Internet addiction. The latter context is argued to be incorrect, since addiction means a negative feeling while flow is positive. Numerous examples follow distinguishing online gamers' repetitive behaviors referring to flow experience from those which refer to addictive behavior.
\end{abstract}

Keywords: flow experience, positive psychology, information technologies, Internet addiction, mimetic flow, repetitive behavior, online gaming.

Optimal experience is a contribution, made over three decades ago, to what is called positive psychology (Seligman \& Csikszentmihalyi, 2000) by one of its leaders, Mihaly Csikszentmihalyi (1975/2000; 1990 and elsewhere). This new paradigm is fully described by Csikszentmihalyis and his followers. While interviewing hundreds of people who would express a deep devotion to their preferred sort of activity (in fact, any type of activity whatsoever), Csikszentmihalyi selected several often reported characteristics of a special feeling common to many of them, which they estimated very highly. This devotion is related to what they believe constitutes an optimal level of their experience.

The study was supported by the Russian Foundation for Basic Research, project No. 08-06-00361a. 
Optimal experience is also known as flow experience. During the interviews, Csikszentmihalyi found that people provide descriptions which are worded almost identically regardless of the particular sort of the preferred activity: almost everyone mentioned "being in the midst of a flow", or, to express it in a slightly different manner, "flowing from one moment to the next, in which he is in control of his actions, and in which there is a little distinction between self and environment, between stimulus and response, or between past, present, and future" (Csikszentmihalyi, 1975/2000, p. 36). No wonder, Csikszentmihalyi (1975/2000; 1990 and elsewhere) called this sort of the holistic experience "flow."

The interviewed people, regardless of their age, gender and culture, professional competence, marital and income status, reported flow as an enjoyment: they confessed they enjoyed the process of doing even hard work. They further confessed enjoying doing it non-stop, sometimes for long time periods, taking risks, or getting painfully tired and sometimes exhausted. They reported they did enjoy it because in return they felt they had been performing to the utmost. No wonder this sort of experience is often called optimal, within the positive psychology paradigm.

The use of information technologies represents a variety of areas to study flow experience (Hoffman \& Novak, 2009; Voiskounsky, 2008). The major areas are:

- Online marketing / shopping,

- E-learning / teaching,

- Cyber-recreation (often, online / computer / video gaming),

- Virtual interaction.

Additionally, less elaborated dimensions include:

- Virtual psychological rehabilitation, such as immersive systems of virtual reality;

- Illicit penetrations into virtual environments and computer security regulations;

- Usability testing, measurement of web-site's attraction, friendliness, adaptation to target populations.

The meaning of the optimal experience is that of a principally positive psychological phenomenon. Within the positive psychology school, flow is universally understood as an enjoying experience with a strong positive impact on the lifestyle and quality of life. 
Among many phenomena which are related to specific patterns of human behavior on the Internet, i.e. in the virtual environments, probably the most important, from both theoretical and practical perspectives, is the one that started a decade and a half ago - it is devoted to psychological qualification of the special type of human dependence, most often called Internet addiction and also known under a multitude of names, such as Internet addiction disorder (IAD), Internet Dependency, Netaholism, Internet overuse, Internet abuse, Problematic Internet use, Pathological Internet use, Excessive Internet use, Compulsive Internet use, Disturbed Internet use, Elevated Internet use, or Internet misuse, as well as less general names stemming from the most popular online services including for example Twitter addiction or FaceBook addiction. The references are numerous, among the latest is an exhaustive and competent review paper by Morahan-Martin (2008).

This paper is not the place to discuss the nature, phenomenology, genesis and status of the Internet related addictions and / or dependencies. We take "addictions" as a generic term, covering all the enumerated types of the Internet misuse. Thus, the Internet addiction refers to every particular web service, such as online gaming, online pornography, online interaction, online romance, online surfing, online gambling, online exploratory behavior, online shopping, etc.

While flow is undoubtedly an enjoyable experience, there is a vivid tendency in the IT environments to associate flow experience with addictive types of behavior, and to investigate the dimensions and parameters of this prospective interconnection (Chen \& Park, 2005; Chiou \& Wan, 2006; Chou \& Ting, 2003; Tzanetakis \& Vitouch, 2002; Wan \& Chiou, 2006). Scholars are making efforts to discover possible mediators between the two types of research data; among such mediators is named for example procrastination (Thatcher, Wretschko \& Fridjhon, 2008). This tendency has been already discussed earlier (Voiskounsky, $2007 ; 2008$ ). It is nevertheless worthwhile to turn to it anew.

In a recent paper (Seah \& Cairns, 2008) video / computer / online game addiction is discussed in the context of immersiveness - the latter has characteristics common to flow experience, though it has been pointed that the two psychological conditions differ. The authors conclude: "Fortunately, videogames do not seem to be the destructive and socially detrimental force that other addictions are. Certainly in some extreme cases, the addiction is as bad as any other ruining relationships 
and destroying lives but on the whole the addicts, and specifically, the highly engaged players in our studies, were able to hold together functional lives and engage in normal social relations. So whilst it may seem that videogame engagement is bad because it leads to addiction, there may be a more hopeful picture. Addiction to videogames could be just a form of high engagement, perhaps no worse than reading a really gripping book and then wanting to read a lot more. Indeed, both authors could claim to have lost sleep and missed meals through reading good books but we would also both claim to have our reading habits firmly under control and integrated into our social and functional lives" (Seah \& Cairns, 2008, p. 62).

An addiction is a sort of an escape from personal problems and a decrease in the quality of life, which are opposite to feelings associated with positive psychological phenomena, including the flow experience. Thus, both theoretically and practically analogies between flow and addiction are inadequate, and any idea to correlate the symptoms of the optimal experience and the Internet addiction will hardly seem justified. Most often the attempts to establish such correlations refer to the parameters of the online / video / computer gaming experience. Indeed, gaming is one of the most addictive of the variety of the IT related behaviors, partly due to the fact that game developers and providers try hard to hook the devoted addicts to their newest products, using for instance some "principles in behavioral conditioning" (Yee, 2006, p. 70).

In their theoretical paper, Chen and Park (2005) discriminate between the two successive types of the online games - MUDs (Multi-user dimensions) and MMORPGs (massive multi-player online role-playing games); rich in visual stimuli, the latter evolved from the text-only-mode MUDs (Bartle, 2003). Chen and Park (2005) believe that MUDs (both adventurous and social) are best suited for the social interaction, while MMORPGs, which supposedly provide the gamers with more levels to match their challenges and their skills, are best suited for experiencing the flow. Though this argument sounds reasonable, it is nevertheless not true, due to the two main reasons.

First, recent studies state that people play MUDs to experience flow, and also to achieve, to interact, and to cognate: these factors are shared by the participants in the samples of Russian, French, US and Chinese gamers (Faiola \& Voiskounsky, 2007; Voiskounsky, Mitina, \& Avetisova, 2004; 2005; 2006a; 2006b; 2008). Second, Bartle (2003), Castronova 
(2007) and others convincingly describe the full multitude of the withingame and outside-of-game channels which the adepts of MMORPGs use for the intensive social interactions. Thus, the discrimination which is so important for Chen and Park (2005) is not at all discriminating. When they state that the MMORPG addicts seek to acquire flow experience, while the MUD addicts seek the chances to get a channel for social interaction, the former statement cannot be accepted, taking into account the abovementioned psychological inequality in the enjoyments inherent of flow and in the addictive types of behavior: the addicts may try to seek for the flow, but unless they recover from the addiction they can hardly reach it.

The opposite idea, namely, that flow causes addiction, is stated in an empirical paper by Chou and Ting (2003). The authors provide a logically reasonable but psychologically insufficient sequence of arguments, namely that "people who enjoy flow experience during an activity may develop a tendency to repeat the activity... Repetition of a particular activity may eventually develop into a tendency toward addiction... Flow experience is the precondition that actually activates addiction" (Chou \& Ting, 2003, p. 665). Moreover, they empirically testify this sequence of statements. Chou and Ting (2003) have in fact testified that the repetitive behavior, not necessarily the flow experience, may activate the addictive activity.

The replication of behaviors intimately associated with the flow, often resulting in the life-long repetitions of the selected, and necessarily enjoyable, activities is indeed characteristic for optimal forms of experience. However, the replications and repetitions are the outer, visible actions taken apart from the inner meaning of such behaviors. The reduction of the flow experience to the repetitive actions is psychologically inadequate, disagreeing with the essence of positive psychology. From the bio-cultural perspective, the psychological meaning of a well-known tendency toward the repetitions of the enjoyable activity is the complete opposite of any sort of the addictive behavior.

Italian supporters of positive psychology Massimini and Delle Fave (2000) introduce the term mimetic flow for the activities which "turn out to be poor in complexity potential, which is an essential feature of authentic flow activities and a prerequisite for individual development. Moreover, such activities do not foster the participant's constructive integration in the culture" (p. 28), on the contrary - they foster a human be- 
ing's marginalization. Examples of the mimetic flow include the intake of drugs and psychoactive substances, stealing, passive leisure activities like watching TV, abuse of technological artifacts (cars, computers, weapons, etc.): "In most cases, there is a misinterpretation of risk behavior as challenging behavior. No connections with individual development and integration in the social context can be found in such practices" (Massimini \& Delle Fave, 2000, p. 29).

Within positive psychology, in order to preserve the enjoyment, repetitive actions should undergo a continuous update of both skills and challenges to their highest possible (utmost) level of matching. The psychological mechanism of a mismatch between the skills and the challenges is described in the study of the specifics of the flow related experience in hacking (Voiskounsky \& Smyslova, 2003a; 2003b), in online gaming (see the abovementioned references) and in web usability (Smyslova \& Voiskounsky, 2009). Such a mismatch, when either an update of the skills does not follow an increase of challenges, or vice versa, means indeed a danger of losing the optimality of experience: as a result a person may turn to a repetitive and possibly addictive type of behavior. But the processes of parallel step-by-step increase of both the skills and the challenges, though not easily attained while hacking, should not raise problems while gaming: the level structure of the popular well-designed games and the abundance of the goals to be pursued guarantee that the players save chances to continue experiencing flow.

An important and theoretically valuable study (Chiou \& Wan, 2006; Wan \& Chiou, 2006) empirically shows that the flow experience is negatively correlated to the Internet addiction. The authors further analysis differentiates satisfactions from dissatisfactions inherent in the online gaming experience, and provides well-justified evidences that in the process of gaming the addicts seek a kind of a relief from their dissatisfaction. Thus, the flow experience and the addictive states have little in common: though the repetitions of certain actions do happen, their psychological nature is entirely incompatible and dissimilar. This result, we believe, hinders further attempts to validate the fact that the cyberspace related addictions and the optimal forms of experience are of the same psychological background.

The correctness of this conclusion is being now thoroughly investigated in a new empirical research project carried out by the author and his postgraduate students; the results of this work in progress will be 
presented by the end of 2010. In this project, two online surveys are administered within the same sample of online gamers, namely a survey on flow experience and a survey on the Internet addiction. When the results are available, it will be clearer if the recent authors (Seah \& Cairns, 2008) were correct saying that online gaming is much more controllable than many other addictive types of the Internet use, and thus that gaming is in a way exclusive, farther from addictive types of behavior and nearer to an optimal type of experience.

\section{References}

Bartle, A. (2003). Designing Virtual Worlds. Indianapolis, IN: New Riders.

Castronova, E. (2007). Exodus to the Virtual World: How Online Fun is Changing Reality. New York, etc.: Palgrave Macmillan.

Chen, J.V., \& Park, Y. (2005). The Difference of Addiction Causes between Massive Multiplayer Online Game and Multi User Domain. International Review of Information Ethics, 4 (12), 53-60.

Chiou, W.-B., \&Wan, C.-S. (2006). A Further Investigation of the Motives of Online Games Addiction. Paper presented at the National Educational Computing Conference (San Diego, July 5-7, 2006). Retrieved August 23, 2006, from http://center.uoregon.edu/ ISTE/uploads/NECC2006/KEY_12738686/Chiou_NECC06ChiouWenBin_RP.pdf

Chou, T.-J., \& Ting, Ch.-Ch. (2003). The Role of Flow Experience in Cyber-Game Addiction. CyberPsychology \& Behavior, 6 (6), 663-675.

Csikszentmihalyi, M. (1990). Flow: The Psychology of Optimal Experience. New York: Harper and Row.

Csikszentmihalyi, M. (1975/2000). Beyond Boredom and Anxiety: Experiencing Flow in Work and Play. San-Francisco: Jossey-Bass.

Faiola A., \& Voiskounsky, A.E. (2007). Flow Experience of MUD Players: Investigating Multi-User Dimension Gamers from the USA. Lecture Notes in Computer Science, 4564, 324-333.

Hoffman, D.L., \& Novak, T.P. (2009). Flow Online: Lessons Learned and Future Prospects. Journal of Interactive Marketing, 23 (1), 23-34.

Massimini, F., \& Delle Fave, A. (2000). Individual Development in a Bio-Cultural Perspective. American Psychologist, 55 (1), 24-33.

Morahan-Martin, J. (2008). Internet Abuse: Emerging Trends and Lingering Questions. In A. Barak(Ed.), Psychological Aspects of Cyberspace: Theory, Research, Applications (pp. 32-69). Cambridge, UK: Cambridge University Press.

Seligman, M.E.P., \& Csikszentmihalyi, M. (2000). Positive Psychology: An Introduction. American Psychologist, 55 (1), 5-14. 
Smyslova, O.V., \& Voiskounsky, A.E. (2009). Usability Studies: To Meet or not to Meet Intrinsic Motivation. PsychNology Journal, 3, 303-324. Retrieved January 30, 2010 from http://www.psychnology.org/File/PNJ7(3)/psychnology_journal_7_3_smyslova. pdf

Thatcher, A., Wretschko, G., \& Fridjhon, P. (2008). Online Flow Experiences, Problematic Internet Use and Internet Procrastination. Computers in Human Behavior, 24 (5), 2236-2254.

Tzanetakis, R., \& Vitouch, P. (2002). Flow-Experience, the Internet and its Relationship to Situation and Personality. Abstract of a paper presented at the Internet Research 3.0: Net/Work/Theory (Maastricht, The Netherlands). Retrieved January 24, 2004, from http://aoir.org/2002/program/tzanetakis.html

Voiskounsky, A.E. (2007). Two Types of Repetitive Experiences on the Internet. INTERFACE: The Journal of Education, Community and Values, 6. Retrieved from http://bcis.pacificu.edu/journal/2007/06/voiskounsky.php

Voiskounsky, A.E. (2008). Flow Experience in Cyberspace: Current Studies and Perspectives. In A. Barak (Ed.). Psychological Aspects of Cyberspace: Theory, Research, Applications (pp. 70-101). Cambridge, UK: Cambridge University Press.

Voiskounsky, A.E., Mitina, O.V., \& Avetisova, A.A. (2004). Playing Online Games: Flow Experience. PsychNology Journal, 2 (3), 259-281. Retrieved November 2, 2004, from http://www.psychnology.org/psychnology_journal_2_3_voiskounsky.pdf

Voiskounsky, A.E., Mitina, O.V., \& Avetisova, A.A. (2005). Communicative Patterns and Flow Experience of MUD Players. International Journal of Advanced Media and Communication, 1 (1), 5-25.

Voiskounsky, A.E., Mitina, O.V., \& Avetisova, A.A. (2006a). Flow Experience and Interaction: Investigation of Francophone Online Gamers. In F. Sudweeks, H. Hrachovec \& Ch. Ess (Eds.), Cultural Attitudes towards Technology and Communication. Proceedings, $5^{\text {th }}$ International Conference (pp. 385-396). Murdoch, Australia: School of Information Technology, Murdoch University.

Voiskounsky, A.E., Mitina, O.V., \& Avetisova, A.A. (2006b). Cross-Cultural Investigation of Online Gaming: Models of Flow Experience and Interaction in Samples of Russian and French Gamers. In Reality and Game \& Game and Reality. Papers of the $37^{\text {th }}$ Annual Conference of the International Simulation and Gaming Association (pp. 64-86). St. Petersburg, Russia: ENGECON.

Voiskounsky, A.E., Mitina, O.V., \& Avetisova, A.A. (2008). Flow Experience and Interaction in Online Gaming: Comparative Study of Russian and Chinese MUD Players. In F. Sudweeks, H. Hrachovec, \& Ch. Ess (Eds.). Sixth International Conference on Cultural Attitudes Towards Technology and Communication (pp. 410-421). Murdoch, Australia: School of Information Technology, Murdoch University.

Voiskounsky, A.E., \& Smyslova, O.V. (2003a). Flow-Based Model of Computer Hackers' Motivation. CyberPsychology \& Behavior, 6 (3), 171-180. 
Voiskounsky, A.E., \& Smyslova, O.V. (2003b). Flow in Computer Hacking: A Model. In C.-C. Chung, C.-K. Kim, W. Kim, T.-W. Ling, \& K.-H. Song (Eds.), Web and Communication Technologies and Internet-Related Social Issues - HSI 2003. Proc., Second International Conference on Human.Society@Internet (Seoul, Korea, June 2003). Lecture Notes in Computer Science, 2713, 176-186.

Wan, C.-S., \& Chion, W.-B. (2006). Psychological Motives and Online Games Addiction: A Test of Flow Theory and Humanistic Needs Theory for Taiwanese Adolescents. CyberPsychology \& Behavior, 9 (3), 317-324.

Yee, N. (2006). The Labor of Fun: How Video Games Blur the Boundaries of Work and Play. Games and Culture, 1, 68-71. 